\title{
Archaeological heritage in the age of digital colonialism
}

\author{
Monika Stobiecka \\ Faculty of 'Artes Liberales', University of Warsaw, Warsaw, Poland \\ Email: m.stobiecka@uw.edu.pl
}

\begin{abstract}
Digital archaeologists claim that their practices have proven to be an important tool for mediating conflict, ensuring that the digital turn in archaeology entails engaging in current political issues. This can be questioned by analysing a copy of the Syrian Arch of Triumph. The original was destroyed in 2015. A year later, a copy was carved out of Egyptian marble; the replica was constructed thanks to digital documentation, which allowed archaeologists to create a 3D model. The arch was placed in various Western locations; however, it never reached Syria. Hybridity, the cultural and political significance of the arch's replica and its 'Grand Tour' invite us to think about different interpretive layers of this artefact of ideological discourse (ontological, epistemological, ethical). In this paper, the replica of the Syrian arch will be analysed through the frameworks of post-colonial theory and technology studies. Both perspectives provide an insight into promising advantages and alarming drawbacks of such digital practices. This paper argues that the case of a copy of the Syrian Arch of Triumph on the one hand reflects the contemporary colonial technocracy in heritage politics (an ethical dimension), and on the other demonstrates that an ideological aspect of its digital reconstruction emerges from a speculative anticipation of what might constitute the universal value of world heritage in the future (an onto-epistemological dimension).
\end{abstract}

Keywords: Post-colonial heritage; nomadic heritage; critical heritage studies; digital archaeology; hybridity; Syrian arch; Palmyra

The Buddhas of Bamiyan in Afghanistan; Aleppo, Bosra and Damascus in Syria; Hatra and Ashur in Iraq are only a few examples of World Heritage sites destroyed during recent serious military conflicts or acts of terrorism. When heritage is threatened as a result of politics, more and more specialists try to find remedies for the inevitable loss. Those tragedies raise awareness of and for heritage also among the general public. The press all over the world are constantly delivering worrying notices on monuments and archaeological sites under threat of contemporary politics.

Archaeologists are particularly interested in and vocal during heated debates on endangered heritage. Their active engagement in current discussions and practices of saving and protecting heritage is immensely inspired by the quick development of new technologies for heritage. The switch from analog to digital in archaeology and a visible shift of focus from destructive practices characteristic of traditional academic archaeology (Schnapp 1996,18) to non-invasive digital and cyber interventions (Forte 2007; 2010; 2014; Favro 2013; Earl 2013; Edgeworth 2015; Roosevelt et al. 2015; Huggett 2015; 2017; Lercari et al. 2016; Levy et al. 2012; Beale and Reilly 2017; Perry 2018) have contributed to the development of a new form of archaeology: digital and cyber rescue archaeology.

Digital and cyber archaeologists generate immense data on endangered heritage (Lercari et al. 2016), create databases and alternative forms of digital heritage (Brown 2007; Berggren et al. 2015; Cooper and Green 2016; Dawson and Reilly 2019), and propose new working patterns for protection and preservation of archaeological monuments and sites (Levy et al. 2012; Jones 
and Levy 2018). Complex technological tools and expanding computer-based skills are being gathered together in new institutional frameworks. More and more, however, mainly Western universities and archaeological faculties are launching dedicated digital and cyber labs; many of them are focused solely on endangered heritage. Western scholars also establish non-profit organizations dedicated to the protection of heritage threatened by destruction. To list just two of these: CyArk (a non-profit organization from Oakland), ${ }^{1}$ and the Center for Cyber-Archaeology and Sustainability (University of San Diego). ${ }^{2}$ Numerous actions are undertaken daily, monthly, yearly to protect and preserve heritage for future generations. However important they are, these practices rarely trigger critical discussion.

The digitization itself raises important questions and serious concerns. Born from military improvement and enhanced during wartime (Brahm 1995; Chambers and Terranova 2014; Stingl 2016), still funded by the military and state agencies, digital technologies have an ambiguous status. As Bernard Stiegler (2016) suggests, using the term pharmacon, technology may be a poison and a cure at the same time. Noting an internal tension within digital technologies applied to protect heritage, archaeologists and heritage specialists should be especially aware and open to theoretical reflection and deep criticism. This, unfortunately, does not happen in every case. Several digital archaeologists themselves point out that digital and cyber-archaeology is under-theorized (Dallas 2015; Huggett 2015; Huvila and Huggett 2018; Perry 2018; Carter 2019; cf. general lack of theory in digital studies: Simanowski 2016) and many researchers in the field have no deeper understanding of their tasks (Huvila and Huggett 2018, 88, cf. Coppelstone and Dunne 2017). Digital archaeology has been accused of 'of being technocratic, apolitical and indifferent to social and cultural concerns and of relating poorly with theoretical orientations currently found in archaeology' (Dallas 2015, 177-178). Dealing with heritage at risk might be called 'archaeodiplomacy' (Lercari et al. $2016,1)$; however, even this notion rarely, if ever, encourages critical perspectives and profound theoretical reflections on heritage politics in the digital era, the meaning of digital heritage, the status of digital archaeological records, or their role in and for different societies (cf. Brown 2007; Morgan and Pallascio 2015). Digital archaeology has been used largely to avoid the politics and ethics of dealing with difficult questions concerning the field of heritage studies.

In this paper, I would like to investigate a post-colonial and neo-colonial discursive potential of the debates on digital heritage. I wish to address the following research questions: what is digital heritage? What is the political role of digital heritage? What is the cultural and spatial setting for digital heritage? Who is producing digital heritage, and where? To whom is digital heritage addressed? And finally, who owns digital heritage?

The last question echoed in multiple discussions concerning the reduced-scale copy of the Syrian arch (Burch 2017; Munawar 2017; Khunti 2018). The copy of the Syrian Arch of Triumph re-created in several Western locations after the original arch was destroyed in Syria in 2015 will illustrate also my arguments. I will place my considerations within the frameworks of post-colonial theory (Bhabha 1994; Young 1995; Gilroy 2004; Coronil 2007; Spivak 2013; Chakrabarty et al. 2016) and its reception in archaeological and heritage studies. My interpretation will be an attempt to tackle multifaceted problems that are inscribed on contemporary digital heritage. I will treat a digital archaeological object, represented by the copy of the Syrian arch, as an embodiment of hybridity - material/digital translation inherited the 'otherness' of the 'digital' (Brahm 1995). I will try to see digital heritage as an onto-epistemological reflection on the contemporary nomadism inherent in the production of such representations that are designed to move across political spaces (Braidotti 1994; 2006; 2013). Further on, I will focus on the ethical issues that stem from the post- and neo-colonial interpretation of the 'Grand Tour' that the Syrian arch has gone through in recent years. Following Ömür Harmanşah, I will use the notion of 'artefacts of ideological discourse' (Harmanşah 2015, 173) as the mirrors reflecting the contemporary iconoclash (Latour 2002). Digital heritage objects treated as artefacts of ideological discourse will allow me to reflect on what Harmanşah describes after Latour as an iconoclash 'the contemporary and perpetual image wars in the public sphere, both destructive and 
constructive and driven by advanced technologies of capitalist hypermodernity, new media mobilisation, and the global economy of the extensive consumption and regeneration of violent imagery' (Harmanşah 2015, 176). I will rework and adjust this definition to consider the post- and neo-colonial character of an insufficiently self-critical or reflexive application of technologies for the (re-)creation of digital archaeological heritage. I am going to claim that a neo-colonial form of oppression, visible through the story of the Syrian arch copy, is sanctioned by a revisited version of the institutionalized heritage dogma: the technocracy (Meskell 2018, 59-89). At the same time, the case of a copy of the Syrian Arch of Triumph demonstrates that the ideological aspect of its digital reconstruction emerges from a speculative anticipation of what might constitute the universal value of world heritage in the future. Therefore the idea of 'universal value' which is based on temporal universality (valuable is what is defined as such in the 20th and 21st centuries) goes against the universality of place and space (digital reconstructions and artefacts might be presented everywhere). In this way, digital archaeological heritage might potentially be considered 'planetary heritage' (Gilroy 2001; 2004; Spivak 2013; Moraru 2015; Chakrabarty et al. 2016) rather than only world heritage.

\section{Copy/paste/relocate: a case of the Syrian Arch of Triumph}

The Arch of Triumph, or the Arch of Septimius Severus, was a Roman ornamental archway in Palmyra, Syria. It was built in the 3rd century A.D. during the reign of the emperor Septimius Severus as an imperial marker of Roman domination in the province (Ward-Perkins 1992). During ancient times, the Syrian arch, together with hundreds of other arch monuments constructed across the Roman provinces, represented a powerful impact of Roman conquest and marked the geopolitical borders of empire (Cassibry 2018). Read from today's perspective, the Syrian arch was a sign of colonial dominance and imperial power that resonated throughout the history of architecture, while arches with a similar political message reappeared in the Renaissance and in the 18th and 19th centuries (Dietler 2005, 44). As a part of the urban architecture of an ancient city, it was widely appreciated and became one of the touristic emblems of Palmyra. Thanks to international archaeological missions it was scrupulously documented (Elcheikh 2019), which turned out to be invaluable when the arch was intentionally destroyed by the Islamic State of Iraq and the Levant (ISIL) in 2015.

Almost a year after this dramatic event, the Institute for Digital Archaeology created a copy of the arch which in April 2016 was set up at Trafalgar Square, London. A few months later, in September 2016, the arch travelled overseas to New York City, where it was placed at the City Hall Park. In February 2017 the copy of the arch was welcomed in Dubai at the World Government Summit. The arch travelled to Italy for one month at the end of March 2017. It was an important landmark in Florence, where the G7 summit had taken place. ${ }^{3}$ At the end of April 2017 the arch was moved to Arona, Italy, where it was presented at the opening of a museum named after Khaled al-Asaad, the Syrian archaeologist and curator of the Palmyra Museum, who lost his life during dramatic events at the archaeological site of Palmyra. The next stop on the arch's tour was Washington, DC, where it was exhibited in September 2018. In 2019 the copy was moved to Switzerland. It was exhibited in Geneva in April during the commemoration of 20 years of the Second Protocol to the Hague Convention, and in Bern in June during the 70th anniversary of Switzerland's commitment to UNESCO. Until now, the last stop in the arch's 'Grand Tour' was Neimënster Abbey in Luxembourg in December 2019, when the arch stood to mark Luxembourg's quarter-century of UNESCO membership.

From its very beginnings, the arch raised multiple questions and controversies. Most of them were summed up by a British archaeologist, Zena Kamash (2017), who conducted a related project at the same time when the replica of the arch was presented in London (Brown 2016). Kamash's project, 'Postcard to Palmyra', was a public-archaeology initiative that invited people to write postcards about the copy of the arch when it was exhibited in London. Kamash gathered a great 
amount of interesting material, which showed that more than a half of responses were positive about the replica; the rest expressed mixed ( 22 per cent) or negative (18 per cent) feelings. Kamash analysed the main fields of concern, which could be summed up as the aim of the replica, technology/information and setting.

The first thought-provoking and problematic issue related to the replica appears while reading the Western press. At the same time, the arch's tour was not widely commented on by the Syrian press. The Syrian Arab News Agency (SANA) mentioned only the first showcase of the replica in London, posting merely a YouTube link. ${ }^{4}$ Similarly, the Middle East monitor dedicated only a six-sentence mention to the first display of the replica. ${ }^{5}$ The rest of showcases were not commented on. What was central to the news I read was rather the reopening of the archaeological site of Palmyra for tourists. SANA presented 17 press releases only from 2019. The Western press devoted many notices to the first and second showcases of the replica. However, multiple articles did not provide comprehensive information on how exactly the copy was created. Kamash comments on this issue and emphasizes that, contrary to how the news media presented this story, the replica was not printed on a 3D printer (Kamash 2017, 613-615; cf. Basulto 2016; Jalabi 2016; Saunders 2017). The technological information was barely understood by journalists and the public at large; however, it is worth stressing that almost all of the popular-press articles about the replica of the Syrian arch were strongly technooptimistic and techno-enthusiastic (Basulto 2016; Saunders 2017). The replica itself was prepared through state-of-the-art 3D technology. This technological method consists of creating a 3D model in dedicated software or from a 3D scan, then an algorithm cuts the model into 2D slices, which are printed one after another (Ma, Li and Yang 2018). As Kamash explains, the replica was machine-cut from a block of marble using a digital model as the template (Kamash 2017, 615). In this case, the importance of advanced digital technologies in the creation of the replica was strongly exaggerated due to misunderstanding and/or lack of information. The Institute of Digital Archaeology did not provide information on the technology, nor on makers, funders or the actual cost of the arch when it was exhibited in London (or elsewhere), which is criticized by Kamash (2017), Stuart Burch (2017), Roshni Khunti (2018) and the Factum Foundation (discussed in Khunti 2018).

The accusations that the replica was 'a grotesque Duchampian readymade that is the fulfilment of ISIS's wishes' (Burch 2017, 72), or that it was 'disneyficated', unethical and unjust towards what had happened to Syrians (Khunti 2018) were not isolated voices of disapproval. I heard similar opinions at the Digital Heritage Congress 2018 in San Francisco. The case of the Syrian arch appeared several times during the debates, mostly in ethical contexts concerning the monetization of heritage, data flows and copyrights. The problem of the data used to create a 3D model turned out to be especially enigmatic. During the discussions in San Francisco, archaeologists and digital specialists mentioned that the Institute of Digital Archaeology copyrighted the replica of the arch. This, of course, undermines the rules of free data flow and accessibility, and moreover the idea of public, universal heritage. Participants at the conference shared other experiences with the arch and its makers, stating that the Institute of Digital Archaeology did not share the data. This problem also runs contrary to the unspoken rules of the digital revolution, which are open-access, open-source and transparency (cf. Wilson and Michalak 2015). Khunti resolved part of those doubts, explaining that the Million Image Database project launched by the Institute of Digital Archaeology to gather more photos of the arch was a voluntary work of people who risked their lives to capture the rubble of the arch (Khunti 2018, 8). Khunti notes the blasé attitude of the Institute of Digital Archaeology, whose acts in this case 'could potentially endanger lives' (ibid.).

Those debates, placed somewhere between capitalization, the politicization of heritage and digital ethics, encouraged me to personally contact the Institute of Digital Archaeology. Noting the sparse communication of the Institute of Digital Archaeology's executives on the official website and on Twitter, I could not find answers to questions that bothered me and were related to the widely understood agency of the replica itself. I was able to get in touch with a representative secretary, after submitting a message on the official website of the Institute of Digital Archaeology. I received an answer stating that I would be contacted by the director of technology, 
Alexy Karenowska, but unfortunately I was left with no further answer. The questions that I sent, hoping that they would be forwarded to Karenowska, touched upon issues of data (using only their own data, data on Creative Commons licenses or other open licenses, data from international databases, an exchange of data), upon the replica's 'Grand Tour' (is the arch being 'rented' by different agendas? Who is the 'owner' of the arch? Who makes decisions about its future destination?), and finally upon whether the arch is going to be exhibited in Syria.

The last question that I wanted to pose to the staff working at the Institute of Digital Archaeology is of particular importance to this paper. It is not only the question of the final destination, but rather a question of multi-spatiality - locations that go with specific politics and cultural settings. The question of politics and settings places this debate in a broader framework of conflict archaeology. As Kamash underlines throughout her extensive research, the grand opening of the arch at Trafalgar Square was an immensely political event. The British archaeologist quotes several postcards, where e.g. the arch is being welcomed in a civilized (my emphasis) world. On the other cards, one can read that the copy may feel colonial or oriental. As Kamash herself states, 'Trafalgar Square, with its monuments to Nelson, military might and the monarchy, is a notoriously imperial space, and yet also strongly associated with protest and anti-imperialism, leading to it being described as a "paradox" and even "schizophrenic" (Kamash 2017, 616). This brief description of the technology used for creating the arch and the geopolitical struggles inscribed in it set introductory points for my further onto-ethical reflections.

\section{The digital 'Other'}

The Institute of Digital Archaeology does not provide full information on the exact makers of the arch; however, the presentation of the team, consisting of a magnetician, an analyst, historians and classical archaeologists, suggests that those might have been the project's participants. ${ }^{6}$ The replica of the Syrian arch was brought to life thanks to digital technologies. No hands were needed to carve the elements of the arch in Egyptian marble - the work was delegated to multiple technological agents: computers, software, models, machinery. However, the effect of that intense digital work is material - a tangible, touchable, solid, 11-ton weighted copy of an arch. In itself, it is neither a 'real' object - the 'real' Arch of Triumph standing in Palmyra - nor a virtual or digital ephemeral scan or another record in a database. As Maurizio Forte $(2007,391-392)$ suggests, those two are not opposed ontologies, but parallel ones, and in this case they entangle in the figure of the 'real' digital material copy. So the replica may be seen as a hybrid, a product of multiple transformations: from an authentic, original, material object into a digital model, and eventually to a material, hyper-realistic, yet reduced-scale, copy. According to Homi K. Bhabha, the hybrid moment, thus 'the transformational value of change[,] lies in the rearticulation, or translation, of elements that are neither the One ... nor the Other ... but something else besides, which contests the terms and territories of both' (Bhabha 1994, 41, original emphasis). The rise of the hybrid is the moment of negotiation between different boundaries and representations (ibid., 41-43). Similarly, the replica becomes a hybrid, following Bhabha's definition. As in a case of post-colonial identities being excluded from strict categories, the idea of digital heritage does not fit standard terms that we use to describe heritage. A digitally copied object is neither an original ('the One', or even 'the normative', 'the traditional', or simply 'the material'), nor is it the facsimile ('the Other', 'the new', 'the modern', or 'the digital'). It shares features with both, but it is never one or the other. The replica is material and tangible; however, it is not original and authentic (discussed in Burch 2017; Munawar 2017; Khunti 2018). At the same time it was created digitally, but it is not immaterial (Buchli 2016). This hybrid is born out of a clash between 'the One' (material and authentic) and 'the Other' (digital and technological); it contests valid categories that we use to describe monuments and artefacts. Hybridity, understood in this way, invites one to create a rupture, to match together unlike things, 'calling attention to disjunctions and conjuctions' (Liebmann 2013, 30). 
The replica is in itself a translation from the 'real' to the 'unreal', a negotiation between the 'original One' and the digital 'Other'. As an object it may seem uncanny, weird, unusual, imaginary, sanitized, alienated - and certainly as lying between the 'well-known' tradition (the Western concept of heritage) and the 'Other' (a copy, something that is unfamiliar for thinking about heritage). 'It is better to fail in originality than to succeed in imitation'; in other words, the common public will always see something normatively 'worse' in a copy. This notion was easily observable in Kamash's research. Her respondents stated that the replica lacks the authenticity of being real, that it is too small or too big, or simply that it does not look aesthetically pleasing (Kamash 2017, 68). Indeed, the copy does not have any specific marks, traces or material features indicating its age, does not bear any signs of pastness (Holtorf 2013). Without pastness the object seems to be a sanitized version of the 'real' that tends to be difficult to engage with (Jeffrey 2015, 145). This 'sterilization of the past' (Shanks 1998), seen as uncanny and unfamiliar, indicates yet another attempt to praise the attachment to Western ideas of monuments and heritage as original, fragmentary, ancient, burdened with Benjamin's aura that suggests the original's uniqueness and duration, as opposed to the copy's transience and reproducibility (Jeffrey 2015; Jones 2017; Jones et al. 2017).

However, the act of translation, the-becoming-of-a-hybrid, brings it agency and a certain value. A transformational value, becoming a hybrid form of heritage, is, according to Fiona Cameron $(2007,57)$,

an active process of value and meaning-making equivalent to that of the physical object. It enacts the curatorial process of selection of what is significant, what should be remembered and forgotten, and what categories of meaning such as classification, cultural values, or aesthetic attributes are given pre-eminence. And the value of the 'real' increases when digitised, enhancing its social, historical, and aesthetic importance, owing to the resources required in the compilation of a $3 \mathrm{D}$ rendering, and through distribution.

The copy in this context is not only about itself, but also about the original as the main reference point. Somehow it resembles the classical structure of postcolonial reasoning, where the Other is always described in the opposition to the Western.

This hybrid form of an 'almost-original' replica of the Syrian arch encourages us to rethink the values that we usually inscribe in the concept of heritage. As a negotiated space it pushes us to think about what is in between. Robert C. Young $(1995,19)$ adds that hybridity suggests the necessity of revising normative estimates. This new form of translated, hybrid heritage creates an important space for negotiation that is formed by flows of information, constant shifts and contestation of values and common thinking (Gunkel 2006; cf. Haraway 1991).

\section{Nomadic heritage}

The replica, in this sense, can be seen as a form of nomadic heritage (cf. Harrison, Appelgren and Bohlin 2018) that correlates with the nomadic theory proposed by Rosi Braidotti (1994; 2006; 2013) and echoes Maurizio Forte's reflection on the cultural nomadism of heritage (2007).

Braidotti defines nomadic subjectivity as contrary to homogeneity, underlining that subjectivity is defined in terms of 'processes of becoming' (Braidotti 2006, 41). Mutating and dynamic subjectivity may help in defining new ideas and affects. The dynamism that characterizes a nomad subject as opposed to standardized patterns invites one to revise conventions (Braidotti 2006, 28-29). In this sense, Braidotti's theory encourages one to rethink contemporary heritage, artefacts and effects of digital works in archaeology (cf. Forte 2010, 10). Migrating artefacts and objects, translated from material to digital form, semi-original hybrids supplemented by digital or cyber aids, are results of care over cultural heritage threatened by conflict and war (Rico 2008; 2014a; 2015; Meskell 2018), but also natural disasters (Rico 2014b; 2016; 2020), 
Anthropocenic effects (cf. Solli et al. 2011; Harrison, Appelgren and Bohlin 2018) and risk societies (Shanks 2012, 32).

There are four boundary conditions for nomadic heritage. First of all, nomadic heritage is in motion. Objects like the copy of the Syrian arch are mobile and transferable; they can be placed everywhere as they are digital and/or material. As 'wandering heritage' they might be considered parallel to the nomadic nature of contemporary social systems (Braidotti 2013) - heritage moves when people are in motion. An idea of 'migrating heritage' as a reflection on the heritage of thirdculture kids (descendants of parents who had been changing countries when their children were young) is vocalized by Laia Colomer (2017). Colomer tackles the problems of globalization, deterritorialization and self-identification with heritage. She notes that more and more societies are being defined as nomad, migrating, in motion; thus she concludes that 'mobility encompasses multiple paths, multiple directions, and multiple relocations. Along these multiple journeys, people perceive, understand and negotiate their different encounters not only in relation to their culture of origin but also according to the experiences gained during their relocations' (ibid., 916). Thus the copy of the arch, while travelling and being set in multiple locations, is becoming a meaningful, agentive artefact of ideological discourse, negotiated by various communities under different spatiotemporal circumstances.

Second, nomadic heritage as portable and movable is always a kind of translated heritage. It is always a result of specialist technological work. It may be fully digital or material-digital, resembling and evoking the original, the 'Real'. The replica of the Syrian arch is an effect of the data flows; thus dynamism, flux and transformation are its core affordances. Unlike precious musealia that hardly ever leave collections and storage, hybrid heritage is predesigned to move. In the case of the replica of the Syrian arch, its most praised and discussed feature is its capability of being relocated and exhibited worldwide, mostly because it can be folded, packed and shipped, and even with a weight of 11 tonnes it needs less legal permission to travel than any other smaller artefact, sculpture or painting.

Third, nomadic heritage in the form of a digital or material object is of compensatory value. It replaces something that has been destroyed, decayed or looted. Thus its creation is always motivated by loss and absence, and as such it generates its own mourning aura by situated social practices. The example of the Syrian arch's copy has its obvious compensatory dimension. As the creators of the replica state,

The goal was to use this installation as a means of sending a message of peace and hope, of demonstrating how new technologies can contribute to the process of restoration and reconstruction, and drawing attention to the importance of helping to protect and preserve the history and heritage of peoples under threat all over the world. ${ }^{7}$

Nomadic heritage brings hope but does not allow one to forget about what has been lost and destroyed.

Fourth, nomadic heritage is an object of visible public interest. This stems directly from its compensatory character and delivers the answer to the questions why and what has been lost. As Kamash proved in her study, the replica did not leave her respondents without a reaction. This artefact of ideological discourse works on affects and emotions; it is not an incomprehensible ruin or a pile of stones - this is a direct political statement, a sign of contemporary conflicts and threats that are widely discussed, commonly known and at least partly understood by the general public.

\section{Digital as ethical?}

Until now I have presented several points that demonstrate the affirmative potential of the Syrian arch's copy. Such a hybrid object allows one to negotiate traditional patterns and concepts, to actualize and appropriate forms of heritage to contemporary social circumstances and conditions. Nevertheless, the Syrian arch's replica raises my true concerns on the ethical level. Here I refer 
mostly to the imperial locations where the replica was placed and exhibited. The arch's 'Grand Tour' and spatio-political settings are circumstances under which the replica may be seen as a failure, given its mission to stand as 'an important gesture of friendship and solidarity with people in the regions of conflict'. ${ }^{8}$ Created and owned by Western agendas, it recalls the long-standing Western ambition of possessing heritage (Thompson 2016).

Going back to the beginnings of the controversial copy, one should note that the Syrian arch's copy was created as a compensatory replacement, a symbol of lost heritage and of the serious implications of terrorism. However, the first question that comes to my mind is - who is actually mourning this loss? As the list of locations where the replica was set suggests, it was the West that felt the most touched by this heritage catastrophe. A Roman archaeological site was destroyed in the course of a terrorist act. So the 'West' reacted with powerful technologies to revive a treasure of universal heritage. Technologies were deployed to create a compensation for the 'West', in the 'West'. Here there are no Syrians struggling with war, migrating, losing their families, their belongings and finally their lives. The replica of the arch is neither about Syrian war, nor about Syrian losses, and never about Syrian heritage. This copy was not created for Syrians as a replacement, as compensation, or as a sign of active disagreement. As the 'Grand Tour' of the fake arch proves, it was created by and for imperial powers to mourn, compensate and prove that heritage is not global. In this sense, the process of re-creation revives and recalls the original meaning of the 'real' arch as a sign of imperial power. By reinvigorating old oriental myths, the West is reaffirming its interest in the Middle East, and so it is creating a target for continued destruction of such sites by those wanting to act against the West. In this sense the restoration of colonial legacy and colonial appropriation of the Graeco-Roman past shall be seen as silent agreement in the neo-colonial oppression that affects further conflicts. One could say, 'the Syrian arch is coming home!' but the home is not Syria - it was Rome, and now it is its ancestor, the West. Heritage is 'Western' (it does not matter whether then or now) and civilized, to paraphrase one of the comments left on a postcard to Palmyra.

The replica is a showcase example of the development of Western technologies. Alexander I. Stingl assumes in his extensive study entitled The digital coloniality of power. Epistemic disobedience in the social sciences and the legitimacy of the digital age, 'Digital Culture is the extension of the very bourgeois civil society that has constituted the Global North ... [it] is ... merely the extension of the coloniality of power and Being' (Stingl 2016, xvii, original emphasis; cf. Mignolo 2007). Stingl connects globalization and digitization as two parallel processes that occurred after the Second World War and strengthened the global primacy and dominance of the 'West'. His study of biotechnologies shows that the 'Other' is currently being colonized by Western, imperial technologies. The West has its skills and innovations, machines and software, and thanks to them it can dominate and conquer those who have not mastered such technologies. Stingl's way of thinking about imperial technologies resembles Coronil's description of American imperialism - a quiet and indirect form of control based on economic dependencies that result in serious imperial effects' (Coronil 2007, 243). Coronil's case study of 9/11 is crucial here - 9/11 is commonly seen as an American symbol of a tragedy, but no one knows and no one questions what happened in Chile on the same date which was a direct effect of American imperial policy (Coronil 2007, 245-246). Information flows and technologies, or, to put it simply, digital culture, contribute to the alienation of the 'Other', of the 'Other's' history, culture and values. The media and messages are 'Western' and prioritize 'Western' interests.

Here, it is also worth recalling Stiegler's notion of a pharmacon - technology can be a cure and a poison at the very same time. The West can manifest its tragedy of losing the Syrian arch by funding a replica and its world tour, one that does not even include Syria. The replica is once again not about people's tragedy and war, but about technological fetishism. Similarly, it recalls the technocratic policy of UNESCO recently discussed by Meskell (2018). Technical skills serve here as efficient tools of 'cultural imperialism' (ibid., 57). This is especially visible while reading press releases entitled 'How 3D printers can help undo the destruction of ISIS' (Basulto 2016), '3D 
printing to preserve heritage. Replica of Palmyra arch draws millions of visitors at fourth installation stop in Arona, Italy' (Saunders 2017), and especially 'The new monument men outsmart ISIS' (Karmelek 2015). The first article presents technologies as a brand-new, powerful weapon: 'ISIS may keep blowing up historical landmarks in the Middle East, but now technology is fighting back' (Basulto 2016). Military nomenclature is even more remarkable at the end of this press notice: 'In short, the terrorists can't win. The architects of the world, armed with only 3D cameras and 3D printers, won't let them' (ibid.). Here one can clearly see how the 'civilized' West is striking back with technologies. After Meskell, it is worth repeating the question: 'exactly who are the "barbarians" in the conflict?' (Meskell 2018, 182).

Lorna-Jane Richardson and Simon Lindgren, while reflecting on the possibility of applying social theory to digital archaeology, point out that a deep social introspection and a critical, reflexive approach in digital archaeology can bring to the discipline an understanding of relationships of power, dominance and inequality (Richardson and Lindgren 2017, 144). This kind of holistic approach to the digital archaeological object was missing when the replica of the Syrian arch was introduced to the different Western locations. Wherever it went, the copy was an artefact of ideological discourse that conveyed direct political statements. In London it was said to be 'a symbol of solidarity with the people of Syria and a symbol of defiance of the barbarians who destroyed the original', serving as a 'schizophrenic' artefact at 'schizophrenic' Trafalgar Square (Kamash 2017). In New York it became 'a powerful act of solidarity with all those hurt and lost in the war in Syria' and 'a historic work of art' exhibited to be admired by New Yorkers. ${ }^{10}$ In Dubai it was said to be 'an embodiment of tradition and high technology.. ${ }^{11}$ In Florence it was placed next to Michelangelo's masterpieces David and Neptune. ${ }^{12}$ In Arona it stood as 'a symbol of unity, optimism, and peace'. ${ }^{13}$ In Washington, DC it was meant to be 'a critical way to celebrate iconic pieces and keep them very much alive and present in our collective consciousness'; it also symbolized 'solidarity with the people of Syria, who have been subjected to such unimaginable horror by ISIS and the Assad Regime'. ${ }^{14}$ Indeed, solidarity is always clearly visible during official political events driven by certain agendas. The last few European stops show even more clearly the hypocrisy, in this case safely hidden under the aegis of UNESCO: in Bern the arch stood as a sign 'for human dignity, against ignorance', to celebrate Switzerland's 70th anniversary of commitment to UNESCO. ${ }^{15}$

The Syrian arch was hijacked by the imperial countries, 'civilized' and possessed thanks to their powerful technological tools, to finally become an artefact of ideological discourse. Of course, one can discuss the role of the 'West' as the protector of world heritage (Meskell 2018), but the question that should be posed touches upon an ethical issue - is it really necessary to say the arch replica serves as a sign of solidarity with Syrians? Taking into consideration the possible costs of production (marble, software, machinery, human labour) and transport (oversea travel from Europe to the United States, the United Arab Emirates, and back and forth), it is really crucial to ask how this artificial substitute of lost heritage could contribute to unity and solidarity with Syrians. What did it change? Did it push and encourage people to react? Or was it only a Disney toy (Kamash 2017, 612, 614; Munawar 2017; Khunti 2018) that helped the 'West' to cover its hypocrisy and boast about new technologies that can fix those acts of 'barbarism'? It seems that the replica did not escape the danger described by Meskell while discussing heritage protection in Syria:

the danger here is intervening in the rescue of purely material heritage, often a Classical antiquity for which Western nations consider themselves to be the legitimate inheritors, while not fully addressing those living and dying through the ongoing conflict or the resultant refugee crisis (Meskell 2018, 183).

Given the discussion by Khunti (2018), who emphasized that countries which welcomed the arch were also those that accepted a minimal number of refugees (the US, the UK and the UAE in 2018), the arch stands as a technological curtain that covers the passiveness of Western countries to actively help the victims of the Syrian conflict. 
Thus, from the above-quoted descriptions of symbols inscribed on the replica of the Syrian arch, only one seems legitimate to me - this copy, as a matter of fact, is nothing more than 'an embodiment of tradition and high technology', whereas tradition sends us back to the ownership of monuments and heritage (Thompson 2016), and high technology means new ways of translating heritage objects into digital or material-digital compensations.

As a citizen of a Second World country, a Pole born and living in Warsaw, a city that was smashed to rubble during the Second World War, I reconsidered Warsaw's Old Town after learning about the Syrian arch copy. Here, an artificial substitute of historic architecture was rebuilt and stands where it should be standing: in Warsaw. Meskell $(2018,150)$ fairly argues that this symbolic site demonstrates 'human resilience to overcome the brutality of war'. By emphasizing my own standpoint and cultural background, I wish to ask for appropriate and ethical digital archaeology that is an effect of meaningful, critical, reflexive studies and works; that is addressed to local communities and their needs to identify with heritage; that produces heritage understood as 'the interaction between people and the world, and between people themselves' (Colomer 2017, 914; after Holtorf and Fairclough 2013). The witness of Syria's tragedies Nour A. Munawar writes, while discussing whether Palmyra should be rebuilt, "The post-conflict reconstruction of Palmyra should be incorporated into the reconciliation of Syrian society with all its divisions, ethnicities, sectors and religions' (Munawar 2017, 43). There is no need for showcase ideological artefacts that serve to justify the 'Western' elite being indifferent and passive about the war in Syria. Digital technologies and their implementation for the sake of heritage at risk should not be covered with flat symbols of ideology that send us directly back to imperialism and colonial narratives (Rico 2008; 2014a; 2014b; Excell and Rico 2013; 2014; Meskell 2018). There is no need for more imperial and exclusive fetishes of Western self-explanation when Palmyra and Syrian heritage have already become the political battlefield, now between the West and Russia. In December 2019 Russia officially confirmed the will to reconstruct the ancient site (Stone 2019; Bishara 2019; Kishkovsky 2019). The agreement was signed after the opening of the Two Palmyras exhibition, which in this political setting drew 'parallels between Palmyra and St. Petersburg' (Bishara 2019).

\section{Conclusions: between neo-colonial digital iconoclash and the need for planetary heritage}

The controversies and unanswered questions related to this study are multiple. Complex problems concerning the ontological, epistemological and, foremost, ethical dimensions of the replica could not be exhaustively addressed here. As I was trying to prove, heritage that is a product of digital workflows has a very ambiguous status. On the ontological level, it may be praised as a new, alternative form that is based on the idea of hybridity, constant negotiation between two apparently antagonistic ontologies - the 'Real' and the (digital) 'Other'. When it comes to ontoepistemological potential, those artificial compensatory forms may be grasped as an embodiment of cultural nomadism: nomadic heritage, constantly in progress, keeping pace with social change and technological development. Seen as nomadic heritage that is in motion and crosses cultural borders, this kind of heritage can be grasped not even as global, but as planetary - beyond the imprisoning categories of current discourse (Gilroy 2001). In introducing the concept of planetary heritage I follow wishes vocalized by Gayatri Chakravorty Spivak. By 'planetary' she understands a particular mindset, where 'there is no choosing between cultures' (Spivak 2013, 451). In this sense, we do not talk about 'their heritage', or 'our heritage', but about shared planetary heritage. As Paul Gilroy (2004, xii) explains, planetary is more intimate, inclined to movement and fluctuation, it opposes a bigger global scale, 'which transmits all the triumphalism and complacency of ever-expanding imperial universals'.

Those affirmative features of planetary heritage may be revealed only if an object, a product of technological flow, is a result of a profoundly reflexive practice, sensibility, engagement with local 
knowledge, subaltern agency and cultural protocols. Otherwise, it may be yet another tool of technological oppression, exclusion or imperialism, especially bearing in mind that most of the world has still no funds to master technologies or to launch specialized digital labs and institutions. The meanings inscribed onto a hybrid, compensatory heritage are of crucial importance for considering it as a thoughtful and needful object of social identification. In the case discussed, heritage could indeed have the power to unite on a more human, emphatic level, not to divide in an imperial way, as it did, in the end.

Bruno Latour $(2002,16)$ describes iconoclash as a moment 'when one does not know, one hesitates, one is troubled by an action for which there is no way to know, without further inquiry, whether it is destructive or constructive'. Indeed, I hesitate to value the Syrian arch copy - on the one hand, it has a creative potential, mirrors hybrid translation, reflects contemporary nomad culture, gives us hope for a more sensitizing and planetary form of heritage; on the other, it comes with obvious post- and neo-colonial implications that raise even more equivocation. The replica is born from destruction; however, is it truly constructive (cf. Rico 2016)? Can we detach different interpretive layers to focus on its affirmative potential? Can we learn our lesson from this obscure tool of political identification?

Latour states $(2002,38)$ that

we had never been modern, but now we are even less so: fragile, frail, threatened; that is, back to normal, back to the anxious and careful stage in which the 'others' used to live before being 'liberated' from their 'absurd beliefs' by our courageous and ambitious modernisation. Suddenly, we seem to cling with a new intensity to our idols, to our fetishes, to our 'factishes', to the extraordinarily fragile ways in which our hand can produce objects over which we have no command.

According to this, where traditional beliefs and patterns are driven by technological improvements and progress to the creation of the meaning(ful/less), we are sentenced to deal with hybrid fetishes that are out of our control, that can be everything and nothing. Instead of using the opportunity to create new forms of heritage on the fertile and active ground of post-destruction landscapes (Rico $2016,19)$, the replica as a form of new heritage is just a wasted chance to truly engage in people's tragedy.

The reason why we challenge destruction is our disagreement over revision and re-evaluation. Many researchers in the field of heritage studies are calling for reconciliation, for an acceptance of destruction and loss (DeSilvey 2017; Holtorf 2018; DeSilvey and Harrison 2020; Rico 2020,). Cornelius Holtorf $(2006,101)$ writes that

destruction and loss are not the opposite of heritage but part of its very substance. It is not the acts of vandals and iconoclasts that are challenging sustainable notions of heritage, but the inability of both academic and political observers to understand and theorise what heritage does, and what is done to it, within the different realities that together make up our one world.

A constant struggle that is inscribed onto the questions of what heritage is, what it does and finally - who owns it, overwhelms minds and prevents breaking with traditions and long-standing conventions. Who owns the rubble of the Syrian arch? Who owns the copy of the Syrian arch?

In a powerful photographic series entitled Imperium Romanum, Austrian photographer Alfred Seiland shows different archaeological sites around the world. Many of them are abandoned, empty, decayed, unfamiliar and uncanny. Seiland's photographs show us a heritage that belongs to nobody, regardless of World Heritage Site status and emblematic appearance (cf. Meskell 2018). In the age of the 'crisis of accumulation' and 'heritagization' (Harrison 2015; Rico 2016; DeSilvey 2017; Meskell 2018; Holtorf 2018; González-Ruibal 2019), everything is protected superficially, 
with a legal framework and a set of documents (Meskell 2018). Specialists do not warmly welcome the wider public to negotiate the meaning of contemporary heritage. It stays in the exclusive zone set by archaeologists, art historians, conservators and, mostly, politicians (Meskell 2018). Heritage is owned when someone makes the decision to own it. In the case of the Syrian arch, the idea of the arch was hijacked by a certain group of interests, copyrighted and praised as the new form of compensatory imperial heritage. The newly announced reconstruction of Palmyra by the Russians is yet another political declaration (Munawar 2017).

The other question that remained unsolved is the following - what else can heritage scholars do than create artificial substitutes that are sufficiently capacious for holding different, often contradictory, meanings? If they are not used to theorize new objects and artefacts of digital provenance, and still want to protect memory and heritage under threat, to engage politically and truly help people who suffer because of war and conflict, then they should probably follow initiatives like the one introduced in Berlin the same year as the replica. In 2016 Germany's Culture Ministry launched the Multaqa ('meeting point') project. The main idea was to recruit and train refugees coming from Syria and Iraq as museum guides to provide native-language tours for fellow refugees, with 'the aim of helping newly arrived people foster connections between Germany's cultural heritage and their own' (Olterman 2016). Keeping in mind that Germany welcomed a great number of refugees, this project not only had profound cultural meaning and social significance, but also was inaugurated to actively engage and help people after the traumatic events that they went through in the conflict zones. There were no blunt slogans, but a straight and explicit message conveyed by this action: 'solidarity with the people of Syria', quoted in this paper for the second time, but here in a more accurate context. If heritage is the interaction between people and the world, and between people themselves, then it is better to resign from the digital armoury and focus on meaning-making through socially situated practices (cf. Jones 2017) heading towards planetary heritage.

\begin{abstract}
Acknowledgements. Here I would like to thank Michael Carter, Ewa Domańska, Ian Hodder and Brendan Weaver for their comments on this paper. This research was conducted during my research stay at the Stanford Archaeology Center, where I studied under the supervision of Ian Hodder and participated in Brendan Weaver's and Barb Voss's course on Archaeology of Colonialism/Postcolonialsms. I would like also to thank all the participants in the course, whose feedback was very important for the final form of this paper. My research stay at the Stanford Archaeology Center wouldn't have been possible without the generous support of the Kościuszko Foundation. The discussions on heritage that I had with Costis Dallas and Michael Shanks were also very meaningful and influenced the argument presented in this paper. I'm also very grateful to Benjamin Hanussek, who discussed migration and the refugee crisis with me, as well as the status of heritage in the Near East. The final response would not have taken its current shape without great help of Agata Kowalewska and inspiring comments delivered by the Unruly Heritage Group members: Torgeir Rinke Bangstad, Mats Burström, Denis Byrne, Tim LeCain, Ewa Domańska, Geneviève Godin, Bjørnar Olsen, Póra Pétursdóttir and Anatolijs Venovcevs. Finally, I'm thankful to Ömür Harmanşah, the associate editor of Archaeological dialogues, the peer reviewers assigned to this manuscript and the editorial committee members, whose comments helped me in improving the general arguments of this paper.
\end{abstract}

\section{Notes}

1 See www.cyark.org.

2 See http://ccas.ucsd.edu.

3 This presentation was widely commented on on Twitter, accused of being a publicity stunt that marginalized actual work done by archaeologists, historians and heritage researchers.

4 See www.sana.sy/en/?p=75268.

5 See www.middleeastmonitor.com/20160419-replica-of-syrias-palmyra-arch-on-display-in-london.

6 Interestingly, one can learn about the Western universities that the staff graduated from, but it is hardly possible to find the exact specializations of people working at the Institute of Digital Archaeology.

7 See http://digitalarchaeology.org.uk/history-of-the-arch.

8 See http://digitalarchaeology.org.uk/building-the-arch.

9 See http://digitalarchaeology.org.uk/trafalgar-information.

10 See http://digitalarchaeology.org.uk/new-york-city.

11 See http://digitalarchaeology.org.uk/dubai.

12 See http://digitalarchaeology.org.uk/florence.
} 
${ }^{13}$ See https://www.archinitaly.org/\#triumphal.

14 See http://digitalarchaeology.org.uk/washington-dc.

${ }^{15}$ See http://digitalarchaeology.org.uk/bern.

\title{
The second coming of Palmyra. A technological prison
}

\author{
Trinidad Rico \\ Rutgers University, Department of Art History, 71 Hamilton St, New Brunswick, NJ 08901, USA \\ Email: trinidad.rico@rutgers.edu
}

Not too long ago, I argued that the untethered proliferation of digital documentation and management strategies in heritage preservation debates and approaches was indicative of a crisis of identity in heritage and preservation studies (Rico 2017). On the one hand, the field has recognized and taken steps to empower marginalized forms of expertise, and on the other hand, it has reinforced expert-led management strategies that are characteristic of technocratic safeguarding measures. At the heart of this tension is a pervasive rhetoric that argues that archiving is saving. But this is not true: having detailed blueprints for a monument may aid in preserving information on its aesthetic, historic and scientific values, but it does not commit to supporting its continuous existence in situ, nor does it recognize its relation to its built and cultural landscape, its communities or its place in history. The reconstruction of the Roman Arch of Septimius Severus in Syria after its destruction in 2015 by the Islamic State of Iraq and the Levant (ISIL) is a good case in point. Efforts to complete and archive detailed documentation over the years, which included 3D scanning, are confronted with the reality of the disappearance of the arch as a casualty of war. Its destruction stands as proof that documentation and reproduction of a site are unrelated to the act of safeguarding it in all its complexity.

The second coming of Palmyra's Arch of Triumph takes the strange shape of a reproduction that is one-third of its original size, made in Italy and put on display across unfamiliar urban landscapes such as Trafalgar Square in London, Madinat Jumeirah in Dubai and Neimënster Abbey in Luxembourg, amongst others. The replica was supposed to head to Syria next, to be unveiled in the city of Tadmur at an undisclosed time, but the COVID-19 pandemic may have interrupted its trajectory. Reactions to the reproduction and circulation of this replica are diverse across the academy, reflecting a struggle in heritage studies as a field that attempts to balance its preservationist legacy with a more recent concern with heritage rights. Perhaps reflecting this tension, while Stobiecka presents a thorough overview of the relative authenticity, hyper-reality and global belonging of this extravagant product, her heritage preservation narrative is missing a more intimate engagement with Syria and Syrians. Without this consideration, a critical discussion of the ethics and politics of technocracy in post-colonial cultural remediation falls short.

Interestingly, despite the relative obscurity of a local beneficiary in this narrative, the collaborative project - which also included the University of Oxford, Harvard University, the Dubai Future Foundation and UNESCO - won the Public Engagement with Research Award, sponsored by the vice chancellor of the University of Oxford (Dubai Future Foundation 2017). Engaging with a plethora of audiences, mostly in Western cities, and countless spectators across the world through its online presence, the travelling Arch of Triumph can be seen as an effective tool for underscoring the significance of preservation in diplomatic transactions and peace-building missions (Meskell 2018). But the way in which a coalition of experts selected each 